Article

\title{
One-Seventh of Patients with COVID-19 Had Olfactory and Gustatory Abnormalities as Their Initial Symptoms: A Systematic Review and Meta-Analysis
}

\author{
Hsin Chi ${ }^{1,2,+}+^{(D)}$ Nan-Chang Chiu 1,2,+(D), Chun-Chih Peng ${ }^{1,2}$, Chao-Hsu Lin ${ }^{3,4}$, Yu-Lin Tai ${ }^{3}$, \\ Ming-Dar Lee ${ }^{3}$, Yu-Jyun Cheng ${ }^{3}$, Boon Fatt Tan ${ }^{5}$ (D) and Chien-Yu Lin ${ }^{2,3, *(D)}$ \\ 1 Department of Pediatrics, MacKay Children's Hospital and MacKay Memorial Hospital, Taipei 10449, \\ Taiwan; chi.4531@mmh.org.tw (H.C.); ncc88@mmh.org.tw (N.-C.C.); pengcc4566@gmail.com (C.-C.P.) \\ 2 Department of Medicine, MacKay Medical College, New Taipei City 25160, Taiwan \\ 3 Department of Pediatrics, Hsinchu MacKay Memorial Hospital, Hsinchu 30071, Taiwan; \\ 3099@mmh.org.tw (C.-H.L.); superlof@gmail.com (Y.-L.T.); 4554@mmh.org.tw (M.-D.L.); \\ 4569@mmh.org.tw (Y.-J.C.) \\ 4 Department of Biological Science and Technology, National Chiao-Tung University, \\ Hsinchu city 30010, Taiwan \\ 5 Department of Pediatric Infectious Disease, National Taiwan University Hospital Hsinchu Branch, \\ Hsinchu city 30059, Taiwan; wenfa80@gmail.com \\ * Correspondence: mmhped.lin@gmail.com; Tel.: +886-3-6119595 \\ $\dagger$ These authors contributed equally to this work.
}

Received: 1 August 2020; Accepted: 20 August 2020; Published: 22 August 2020

\begin{abstract}
Coronavirus disease 2019 (COVID-19) patients exhibited protean clinical manifestations. Olfactory and gustatory abnormalities (anosmia and ageusia) were observed in COVID-19 patients, but the reported prevalence varied. In this systematic review, the prevalence of olfactory and gustatory abnormalities (OGA) was evaluated in laboratory-confirmed COVID-19 patients. On 8 May 2020, 14,506 articles were screened, while 12 of them were enrolled. A total of 1739 COVID-19 patients were analyzed, with a wide range of prevalence observed (5.6-94\%). The pooled prevalence was $48.5 \%$ with high heterogeneity $\left(I^{2}, 98.8 \% ; p<0.0001\right)$. In total, $15.5 \%$ had OGA as their first symptom $\left(I^{2}, 22.6 \%\right.$; $p=0.27)$ among the patients analyzed. Contradictory to COVID-19 negative controls, patients with COVID-19 had a higher risk of OGA (odds ratio, $5.3 ; I^{2}, 66.5 \% ; p=0.03$ ). In conclusion, approximately half of COVID-19 patients had OGA, and one-seventh of them had OGA as their initial symptoms. OGA were cardinal symptoms of COVID-19, which may serve as clues for early diagnosis. Diagnostic testing for SARS-CoV-2 was suggested in patients with OGA during the COVID-19 pandemic to ensure timely diagnosis and appropriate quarantine.
\end{abstract}

Keywords: COVID-19; novel coronavirus; SARS-CoV-2; anosmia; ageusia

\section{Introduction}

The emerging crisis of the coronavirus disease 2019 (COVID-19) was caused by Severe Acute Respiratory Syndrome Coronavirus 2 (SARS-CoV-2) and became a huge burden to the world. As of July 2020, there were more than 100 million infected people and 500 thousand deaths worldwide [1]. Approximately $5 \%$ of patients required invasive care and the case fatality rate may be $40 \%$ in these patients [2]. The optimal strategies to combat COVID-19 varied across countries, however, timely diagnosis, prompt quarantine, and treatment play crucial roles for successful management $[3,4]$. 
The incubation period was approximately five days, while fever and respiratory symptoms were major symptoms of the disease $[5,6]$. However, the full disease entity remained largely unclear. Olfactory and gustatory abnormalities (anosmia and ageusia), which were not reported in earlier studies in China, were observed in March 2020. These symptoms were easily overlooked, but a wide range of prevalence was reported. In Mao's study, approximately $5 \%$ of COVID- 19 patients had OGA, while two-thirds had OGA in Luers' study $[7,8]$. The prevalence of OGA among patients with COVID-19 caught our attention, thus, the possible role of OGA as red flags to initiate diagnostic testing needed to be further clarified. Therefore, this systematic review was conducted to investigate the prevalence of OGA in COVID-19 patients.

\section{Materials and Methods}

\subsection{Study Design and Literature Search}

This study was approved by the Institutional Review Board of the MacKay Memorial Hospital, Taipei, Taiwan (approval number, 20MMHIS140e) and was conducted in accordance with the Preferred Reporting Items for Systematic Reviews and Meta-analyses (PRISMA) guidelines [9,10]. Comprehensive keywords were used, such as "COVID-19", "COVID-2019", "severe acute respiratory syndrome coronavirus 2", "2019-nCoV", "2019nCoV", "SARS-CoV-2", and "Wuhan" with Boolean operators and $\mathrm{MeSH}$ terms. Electronic medical databases were searched from inception to 8 May 2020, including PubMed/Medline, EMBASE, Cumulative Index to Nursing and Allied Health Literature, National Digital Library of Theses and Dissertations in Taiwan database, Art Image Indexing Service on the Internet Database (Chinese database), and the Cochrane database. The search was independently performed by two authors, and disagreements were resolved through a discussion with the third author. No constraints were placed on language, year of publication, and participant characteristics to ensure a comprehensive search and identify the maximum number of potential articles. Authors were contacted to obtain additional information when necessary.

\subsection{Study Selection and Data Extraction}

Studies investigating "olfactory", "gustatory", "smell", "taste", "anosmia", "hyposmia", "ageusia", and "hypogeusia" were analyzed. The exclusion criteria were as follows: duplicate publications, irrelevant articles, studies where the infection status was not clearly confirmed, studies that did not evaluate clinical outcomes, simple case reports, and review articles. Primary outcomes were the prevalence of OGA, respectively.

Furthermore, two authors independently appraised the selected articles and extracted the following data: name of the first author, study country, participant population, demographic data, OGA prevalence, OGA tests, onset time, recovery time, and COVID-19 test results. In case of disagreement between the two authors, consensus was reached through a discussion with the third author. Quality assessments were conducted independently by two authors based on the domains of selection, ascertainment, causality, and reporting.

\subsection{Statistical Analyses}

If meta-analysis was performed, a random-effect regression model was utilized assuming that the true effect size was not the same. Heterogeneity was further quantified using Cochran's $\mathrm{Q}$ test and $I^{2}$ statistics. A $p$ value less than 0.05 was considered statistically significant. MedCalc (MedCalc software, Belgium) v18 was used for statistical analyses.

\section{Results}

As of 8 May 2020, 14,506 non-duplicated articles were selected from the medical research database, and the titles and abstracts of all articles were screened. Twelve studies fulfilling the inclusion and exclusion criteria were included in the final systematic review (Table 1) [7,8,11-20]. Six studies were 
conducted in Europe, four in the USA, one in China, and one in Iran. A total of 1739 participants were identified, and the pooled prevalence was $48.5 \%\left(I^{2}, 98.8 \% ; p<0.0001\right)$ (Figure 1$)$. Five studies involving 471 individuals reported the onset of OGA, and 15.5\% of the patients had OGA as initial symptoms (Figure 2) (pooled prevalence, $15.5 \% ; I^{2}, 22.6 \% ; p=0.27$ ). Four studies comparing COVID-19 patients and negative controls possessed a higher risk of OGA (Figure 3) (odds ratio, $5.3 ; I^{2}, 66.5 \%$; $p=0.0297$ ). The funnel plots were plotted and showed no significant asymmetry (Supplementary Figures S1-S3).

Table 1. Demographic characteristics of enrolled studies investigating OGA.

\begin{tabular}{|c|c|c|c|c|c|c|c|}
\hline Study [Ref.] & Country & $\begin{array}{c}\text { Study } \\
\text { Population }\end{array}$ & $\begin{array}{c}\text { Study } \\
\text { Participants, N }\end{array}$ & $\begin{array}{l}\text { Patients with } \\
\text { OGA, N (\%) }\end{array}$ & $\begin{array}{c}\text { OGA as Initial } \\
\text { Presentation, } \mathbf{N} \\
(\%)\end{array}$ & $\begin{array}{c}\text { Controls, } \\
\mathbf{N}\end{array}$ & $\begin{array}{l}\text { Controls with } \\
\text { OGA, N (\%) }\end{array}$ \\
\hline Aggarwal [11] & USA & $\begin{array}{l}\text { hospitalized } \\
\text { patients }\end{array}$ & 16 & $3(18.8)$ & & & \\
\hline Beltrán-Corbellini [12] & Spain & $\begin{array}{l}\text { hospitalized } \\
\text { patients }\end{array}$ & 79 & $31(39.2)$ & $11(13.9)$ & 40 & $5(12.5)$ \\
\hline Giacomelli [13] & Italy & $\begin{array}{l}\text { hospitalized } \\
\text { patients }\end{array}$ & 59 & $20(33.9)$ & $12(20.3)$ & & \\
\hline Luers [7] & Germany & not reported & 72 & $54(75)$ & $10(13.9)$ & & \\
\hline Mao [8] & China & $\begin{array}{l}\text { hospitalized } \\
\text { patients }\end{array}$ & 214 & $12(5.6)$ & & & \\
\hline Moein [15] & Iran & $\begin{array}{l}\text { mild, moderate, } \\
\text { severe }\end{array}$ & 60 & $21(35)$ & & 60 & $11(18.3)$ \\
\hline Roland [16] & USA & $\begin{array}{l}\text { hospitalized and } \\
\text { outpatients }\end{array}$ & 145 & $95(66)$ & & 157 & $42(26.8)$ \\
\hline Yan [20] & USA & $\begin{array}{c}\text { hospitalized and } \\
\text { outpatients }\end{array}$ & 128 & 75 (58.6) & & & \\
\hline Total & & & 1739 & 907 (48.5) & $70(15.5)$ & 460 & $93(20.2)$ \\
\hline
\end{tabular}

Abbreviations: OGA—olfactory and gustatory abnormalities; Controls-COVID-19 negative controls; Ref.-reference.

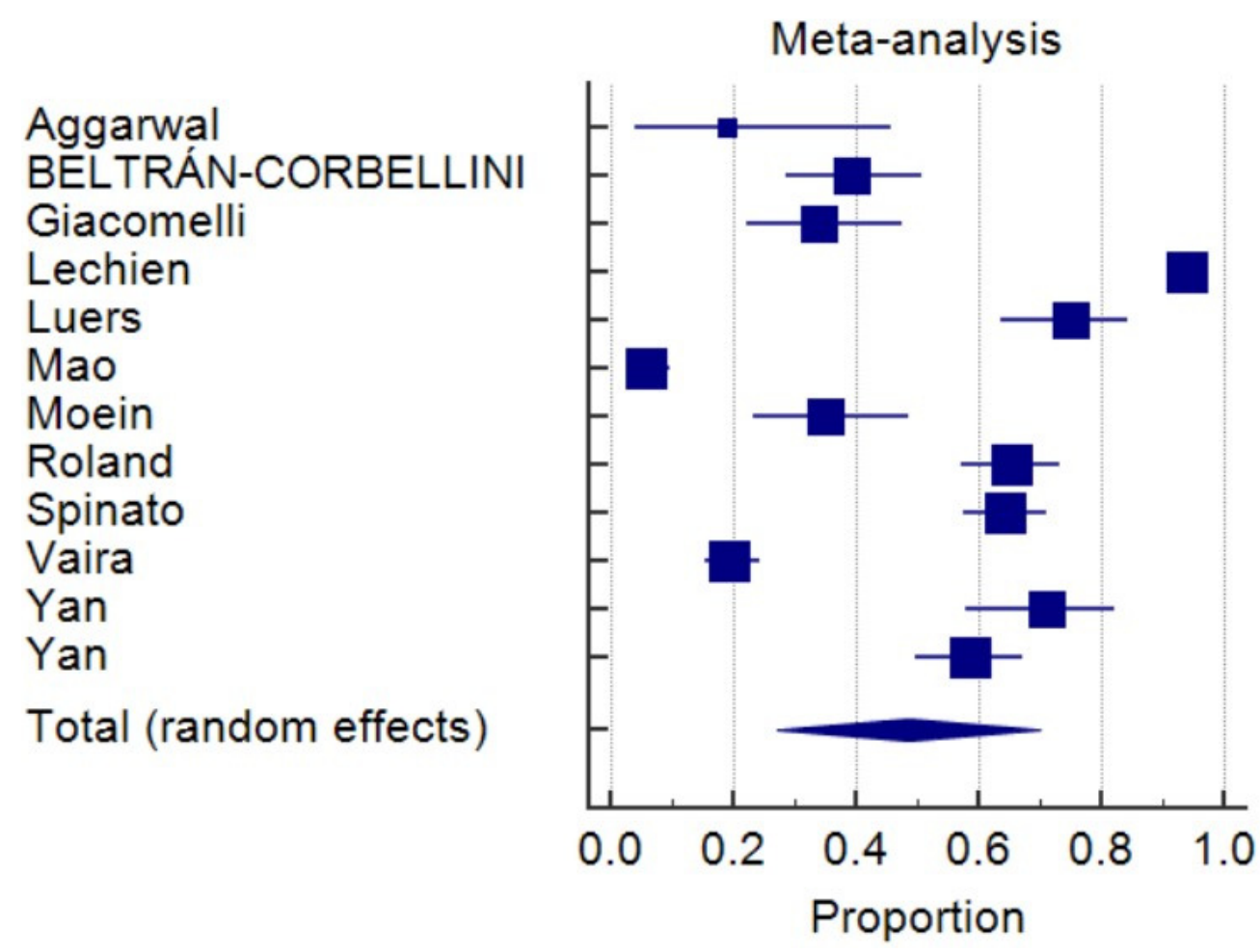

Figure 1. Forest plot of prevalence of olfactory and gustatory abnormalities. The pooled prevalence was $48.5 \%\left(I^{2}, 98.8 \% ; p<0.0001\right)$. 


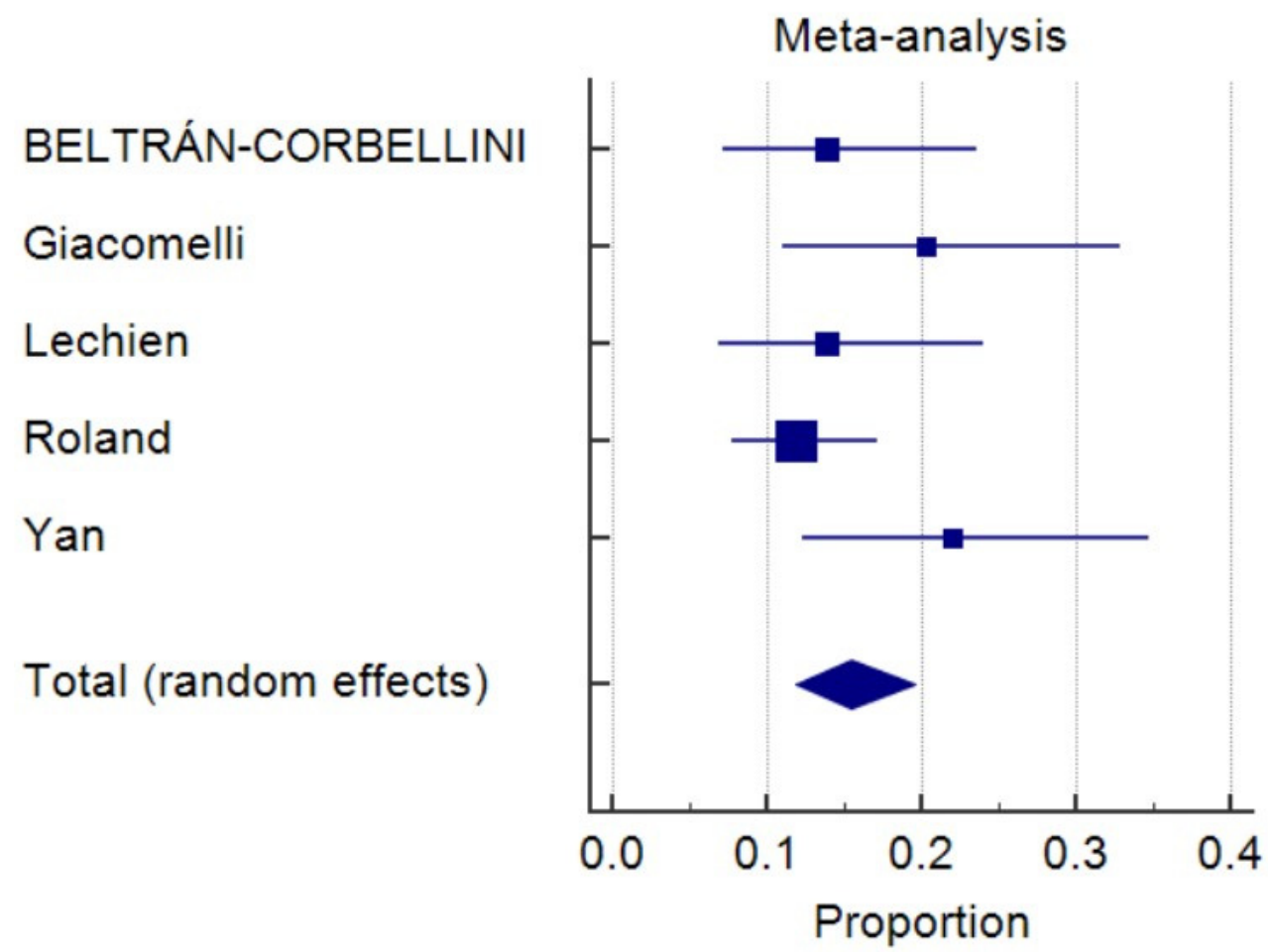

Figure 2. Forest plot of prevalence of olfactory and gustatory abnormalities as initial symptoms (pooled prevalence, $\left.15.5 \% ; I^{2}, 22.6 \% ; p=0.27\right)$.

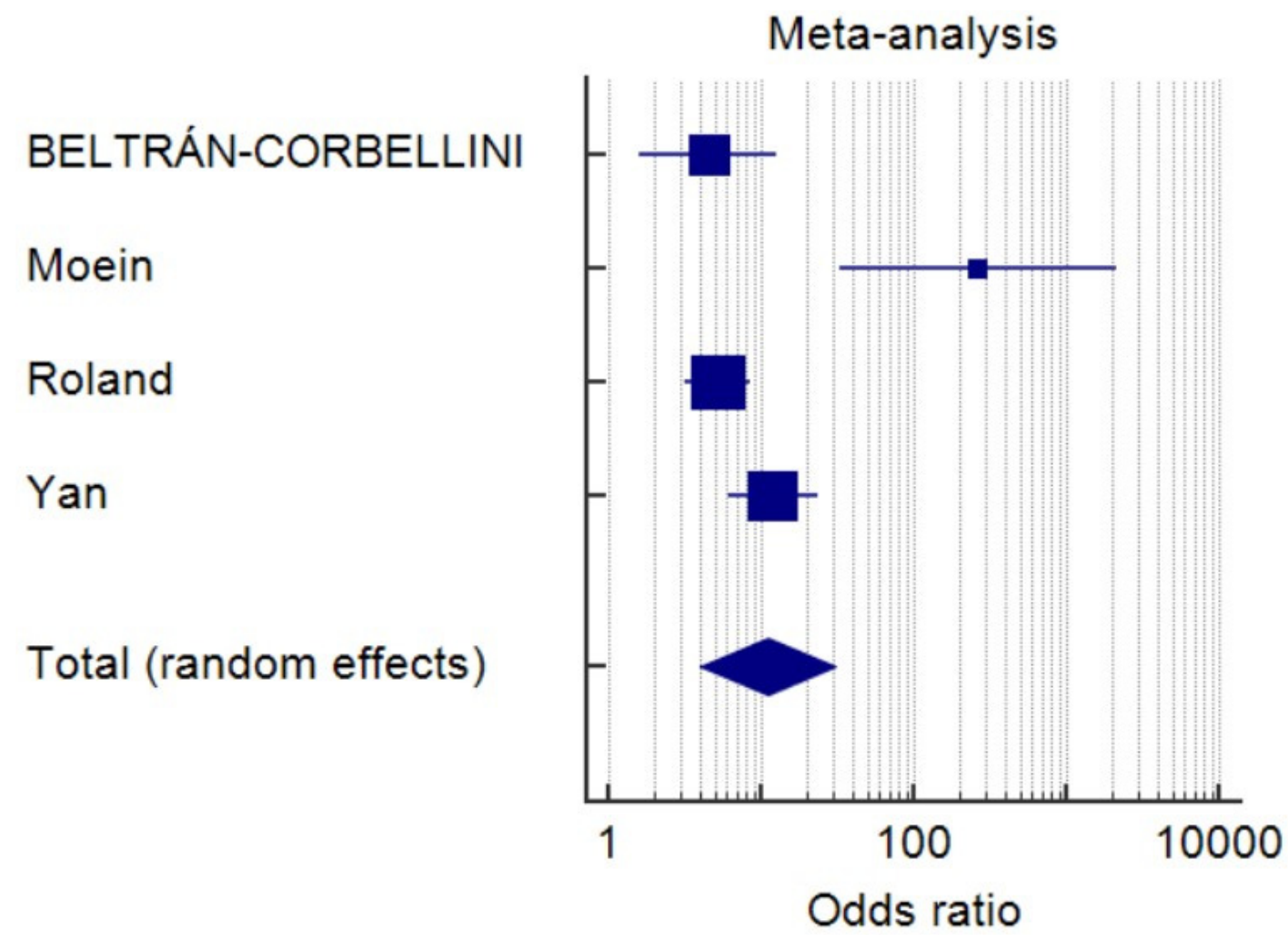

Figure 3. Forest plot of enrolled studies investigating the odds ratio of olfactory and gustatory abnormalities in COVID-19 patients and controls without COVID-19. (Odds ratio, 5.3; $I^{2}, 66.5 \%$; $p=0.03)$. 


\section{Discussion}

Based on our systematic review, there was a high prevalence of OGA in COVID-19 patients, and $15.5 \%$ had OGA as their first symptom. Compared with controls, patients with COVID-19 had a higher risk of OGA (odds ratio, 5.3). OGA were cardinal symptoms of COVID-19, which might serve as a clue for early diagnosis. Patients with OGA should receive diagnostic testing for SARS-CoV-2 during the COVID-19 pandemic to initiate early diagnosis, appropriate quarantine, and treatment.

COVID-19 patients had protean clinical manifestations. Moreover, several diseases may cause OGA. OGA were observed in patients with allergic rhinitis and respiratory virus infection, such as influenza and other coronaviruses [12]. We found a higher risk of OGA in patients with COVID-19 and OGA was the initial presentation in one-seventh of patients. Therefore, patients exhibiting OGA should undergo SARS-CoV-2 testing during the COVID-19 pandemic. However, the exact pathogenesis of COVID-19 remained largely unclear. OGA may result from direct virus invasion of the central nervous system or peripheral nerves [21]. Angiotensin-converting enzyme 2 (ACE2) was believed to be involved in the pathogenesis of COVID-19. Increased expression of ACE2 receptors in olfactory-specific horizontal basal cells and sustentacular cells were reported; thus, retrograde injury of the peripheral nervous system may cause OGA in COVID-19 patients. Further studies are required to clarify the underpinning pathogenesis of OGA in COVID-19.

There were some systematic reviews investigating the prevalence of OGA in patients with COVID-19 published recently [22-24]. In total, 43.93-52.73\% patients were reported to have OGA [22]. Half patients had OGA in Hoang's study [23]. Costa et al. also had similar findings (56.4-60.7\%) [24]. Two recent studies investigating the prevalence of OGA in Italy were reported by Vaira. They found the prevalence of OGA was $73.6 \%(53 / 72)$ and $74.2 \%(256 / 345)[25,26]$. Our findings were consistent with these reports and the high prevalence of OGA in COVID-19 was reemphasized. Furthermore, we analyzed the proportion of OGA as the initial symptoms, which was not clearly reported previously, and found one-seventh (15.5\%) of patients with COVID-19 had OGA as their first symptoms. The presence of OGA before onset of fever, cough, and other respiratory symptoms provided clues for early diagnosis of COVID-19. Timely diagnosis and prompt quarantine ensured adequate containment of disease and was helpful to identify possible infected people in areas with limited diagnostic resources.

The wide range of reported prevalence may be attributed to the diagnostic methods. Most OGA were self-reported and might be easily overlooked. Changes of nasal tactile sensitivity were reported in patients with OGA and may provide an objective and reliable diagnostic reference for physicians [27]. During the COVID-19 pandemic, home quarantine was an important strategy to contain disease and onsite tests for OGA in hospitals were not always available. Objective tests were a challenge in such situations. Vaira et al. developed a self-administered olfactory and gustatory test using solutions with different concentrations to determine the olfactory and gustatory thresholds at home [28]. There was no significant difference between this remote evaluation and hospital validation tests. This practice was feasible and more reliable. Furthermore, they found 256 COVID-19 patients $(74.2 \%)$ had self-reported OGA in the multi-center study in Italy; they performed objective tests in patients without self-reported OGA. Twenty-seven patients (30.3\%) were found to have objectively mild hyposmia [26]. These findings indicated the potential risk of underestimating of OGA in patients of COVID-19 and emphasized the important role of objective tests in future studies.

The high prevalence of OGA was observed in our systematic review, and high heterogeneity was found. An extraordinary low prevalence (5.6\%) of OGA was reported in Mao's study conducted in China. Further subgroup analysis by geographic areas was performed, which revealed a $55.8 \%$ prevalence in Europe $\left(I^{2}, 99.12 \% ; p<0.0001\right)$ and $54.9 \%$ in the USA $\left(I^{2}, 87.18 \% ; p=0.0004\right)$. Further studies are warranted to investigate possible differences between races and countries.

Compared with other respiratory viruses, SARS-CoV-2 infection had a longer disease course and the duration of OGA was investigated [26]. A long duration of olfactory abnormality was observed and approximately $70 \%$ patients had OGA after 1 month. However, the severity of olfactory abnormality improved rapidly after the first 10 days. Gustatory dysfunction was less durable and $55 \%$ patients 
returned to normal gustatory function after the third week. Interestingly, the severity of OGA was not correlated to the severity of COVID-19 illness; however, a longer duration of OGA $>7$ days might have higher risk of severe COVID-19. Further studies are required to clarify the correlation and underpinning pathophysiology between OGA and COVID-19.

Our study was subject to some limitations. First, OGA were self-reported symptoms, and some studies were retrospective. Recalling bias may exist which calls for a randomized prospective study. Second, nasal and tongue mucosa biopsy and other biomarkers were not tested, and the underlying pathophysiology between OGA and COVID-19 was not explored. Although our systematic review reported a strong correlation between OGA and COVID-19, further studies are warranted to elucidate the causal pathogenesis.

\section{Conclusions}

In conclusion, this systematic review and meta-analysis identified 1739 laboratory-confirmed COVID-19 patients, and we found that approximately half of the patients had OGA. Approximately one-seventh of the patients had OGA as their initial presentation; thus, the presence of OGA may provide a clue for early diagnosis. Compared with controls, patients with COVID-19 had higher risk of OGA. Diagnostic testing for SARS-CoV-2 was suggested in patients with OGA during the COVID-19 pandemic.

Supplementary Materials: The following are available online at http://www.mdpi.com/2075-1729/10/9/158/s1, Figure S1: Funnel plot of enrolled studies investigating the prevalence of olfactory and gustatory abnormalities; Figure S2: Funnel plot of enrolled studies investigating the prevalence of olfactory and gustatory abnormalities as initial symptoms; Figure S3: Funnel plot of enrolled studies investigating the prevalence of olfactory and gustatory abnormalities between COVID-19 and controls.

Author Contributions: Conceptualization, H.C., N.-C.C. and C.-Y.L.; methodology, C.-C.P., M.-D.L. and C.-H.L.; software, Y.-L.T. and Y.-J.C.; validation, H.C., C.-C.P. and B.F.T.; formal analysis, N.-C.C., C.-H.L. and C.-Y.L.; investigation, N.-C.C., M.-D.L. and Y.-L.T.; writing-original draft preparation, C.-Y.L.; writing-review and editing, H.C. and N.-C.C. contributed to this work equally. All authors have read and agreed to the published version of the manuscript.

Funding: This research received no external funding.

Conflicts of Interest: The authors declare no conflict of interest.

\section{References}

1. WHO. Coronavirus Disease (Covid-19) Outbreak Situation. Available online: https://www.who.int/ emergencies/diseases/novel-coronavirus-2019 (accessed on 1 July 2020).

2. Wiersinga, W.J.; Rhodes, A.; Cheng, A.C.; Peacock, S.J.; Prescott, H.C. Pathophysiology, transmission, diagnosis, and treatment of coronavirus disease 2019 (covid-19): A review. JAMA 2020. [CrossRef] [PubMed]

3. Chang, C.-M.; Tan, T.-W.; Ho, T.-C.; Chen, C.-C.; Su, T.-H.; Lin, C.-Y. Covid-19: Taiwan's epidemiological characteristics and public and hospital responses. PeerJ 2020, 8, e9360. [CrossRef] [PubMed]

4. Chiu, N.-C.; Chi, H.; Tai, Y.-L.; Peng, C.-C.; Tseng, C.-Y.; Chen, C.-C.; Tan, B.F.; Lin, C.Y. Impact of wearing masks, hand hygiene, and social distancing on influenza, enterovirus, and all-cause pneumonia during the coronavirus pandemic: Retrospective national epidemiological surveillance study. J. Med. Internet. Res. 2020, 22, e21257. [CrossRef] [PubMed]

5. Wu, Z.; McGoogan, J.M. Characteristics of and important lessons from the coronavirus disease 2019 (covid-19) outbreak in china: Summary of a report of 72314 cases from the Chinese center for disease control and prevention. JAMA 2020. [CrossRef]

6. Lee, P.I.; Hsueh, P.R. Emerging threats from zoonotic coronaviruses-from sars and mers to 2019-ncov. J. Microbiol. Immunol. Infect. 2020, 53, 365-367. [CrossRef]

7. Luers, J.C.; Rokohl, A.C.; Loreck, N.; Wawer Matos, P.A.; Augustin, M.; Dewald, F.; Klein, F.; Lehmann, C.; Heindl, L.M. Olfactory and gustatory dysfunction in coronavirus disease 19 (covid-19). Clin. Infect. Dis. 2020. [CrossRef] 
8. Mao, L.; Jin, H.; Wang, M.; Hu, Y.; Chen, S.; He, Q.; Chang, J.; Hong, C.; Zhou, Y.; Wang, D.; et al. Neurologic manifestations of hospitalized patients with coronavirus disease 2019 in wuhan, china. JAMA Neurol. 2020, 77, 1-9. [CrossRef]

9. Shamseer, L.; Moher, D.; Clarke, M.; Ghersi, D.; Liberati, A.; Petticrew, M.; Shekelle, P.; Stewart, L.A. Preferred reporting items for systematic review and meta-analysis protocols (prisma-p) 2015: Elaboration and explanation. BMJ 2015, 350, g7647. [CrossRef]

10. Chi, H.; Chiu, N.-C.; Tai, Y.-L.; Chang, H.-Y.; Lin, C.-H.; Sung, Y.-H.; Tseng, C.-Y.T.; Liu, L.Y.-M.; Lin, C.-Y. Clinical features of neonates born to mothers with coronavirus disease-2019: A systematic review of 105 neonates. J. Microbiol. Immunol. Infect. 2020. [CrossRef]

11. Aggarwal, S.; Garcia-Telles, N.; Aggarwal, G.; Lavie, C.; Lippi, G.; Henry, B.M. Clinical features, laboratory characteristics, and outcomes of patients hospitalized with coronavirus disease 2019 (covid-19): Early report from the united states. Diagnosis (Berl) 2020, 7, 91-96. [CrossRef]

12. Beltran-Corbellini, A.; Chico-Garcia, J.L.; Martinez-Poles, J.; Rodriguez-Jorge, F.; Natera-Villalba, E.; Gomez-Corral, J.; Gomez-Lopez, A.; Monreal, E.; Parra-Diaz, P.; Cortes-Cuevas, J.L.; et al. Acute-onset smell and taste disorders in the context of covid-19: A pilot multicenter pcr-based case-control study. Eur. J. Neurol. 2020. [CrossRef]

13. Giacomelli, A.; Pezzati, L.; Conti, F.; Bernacchia, D.; Siano, M.; Oreni, L.; Rusconi, S.; Gervasoni, C.; Ridolfo, A.L.; Rizzardini, G.; et al. Self-reported olfactory and taste disorders in patients with severe acute respiratory coronavirus 2 infection: A cross-sectional study. Clin. Infect. Dis. 2020, 71, 889-890. [CrossRef] [PubMed]

14. Lechien, J.R.; Chiesa-Estomba, C.M.; De Siati, D.R.; Horoi, M.; Le Bon, S.D.; Rodriguez, A.; Dequanter, D.; Blecic, S.; El Afia, F.; Distinguin, L.; et al. Olfactory and gustatory dysfunctions as a clinical presentation of mild-to-moderate forms of the coronavirus disease (covid-19): A multicenter European study. Eur. Arch. Otorhinolaryngol. 2020, 277, 2251-2261. [CrossRef]

15. Moein, S.T.; Hashemian, S.M.R.; Mansourafshar, B.; Khorram-Tousi, A.; Tabarsi, P.; Doty, R.L. Smell dysfunction: A biomarker for covid-19. Int. Forum Allergy Rhinol. 2020, 10, 944-950. [CrossRef] [PubMed]

16. Roland, L.T.; Gurrola, J.G., 2nd; Loftus, P.A.; Cheung, S.W.; Chang, J.L. Smell and taste symptom-based predictive model for covid-19 diagnosis. Int. Forum. Allergy Rhinol. 2020, 10, 832-838. [CrossRef]

17. Spinato, G.; Fabbris, C.; Polesel, J.; Cazzador, D.; Borsetto, D.; Hopkins, C.; Boscolo-Rizzo, P. Alterations in smell or taste in mildly symptomatic outpatients with sars-cov-2 infection. JAMA 2020, 323, 2089-2090. [CrossRef] [PubMed]

18. Vaira, L.A.; Salzano, G.; Deiana, G.; De Riu, G. Anosmia and ageusia: Common findings in covid-19 patients. Laryngoscope 2020, 130, 1787. [CrossRef] [PubMed]

19. Yan, C.H.; Faraji, F.; Prajapati, D.P.; Boone, C.E.; DeConde, A.S. Association of chemosensory dysfunction and covid-19 in patients presenting with influenza-like symptoms. Int. Forum Allergy Rhinol. 2020, 10, 806-813. [CrossRef]

20. Yan, C.H.; Faraji, F.; Prajapati, D.P.; Ostrander, B.T.; DeConde, A.S. Self-reported olfactory loss associates with outpatient clinical course in covid-19. Int. Forum Allergy Rhinol 2020, 10, 821-831. [CrossRef]

21. Vaira, L.A.; Salzano, G.; Fois, A.G.; Piombino, P.; De Riu, G. Potential pathogenesis of ageusia and anosmia in covid-19 patients. Int Forum Allergy Rhinol 2020. [CrossRef]

22. Tong, J.Y.; Wong, A.; Zhu, D.; Fastenberg, J.H.; Tham, T. The prevalence of olfactory and gustatory dysfunction in covid-19 patients: A systematic review and meta-analysis. Otolaryngol. Head Neck Surg. 2020, 163, 3-11. [CrossRef] [PubMed]

23. Hoang, M.P.; Kanjanaumporn, J.; Aeumjaturapat, S.; Chusakul, S.; Seresirikachorn, K.; Snidvongs, K. Olfactory and gustatory dysfunctions in covid-19 patients: A systematic review and meta-analysis. Asian Pac. J. Allergy Immunol. 2020. [CrossRef]

24. da Costa, K.V.; Carnaúba, A.T.L.; Rocha, K.W.; de Andrade, K.C.L.; Ferreira, S.M.; Menezes, P.D.L. Olfactory and taste disorders in covid-19: A systematic review. Braz. J. Otorhinolaryngol. 2020. [CrossRef]

25. Vaira, L.A.; Deiana, G.; Fois, A.G.; Pirina, P.; Madeddu, G.; De Vito, A.; Babudieri, S.; Petrocelli, M.; Serra, A.; Bussu, F.; et al. Objective evaluation of anosmia and ageusia in covid-19 patients: Single-center experience on 72 cases. Head Neck 2020, 42, 1252-1258. [CrossRef] [PubMed] 
26. Vaira, L.A.; Hopkins, C.; Salzano, G.; Petrocelli, M.; Melis, A.; Cucurullo, M.; Ferrari, M.; Gagliardini, L.; Pipolo, C.; Deiana, G.; et al. Olfactory and gustatory function impairment in covid-19 patients: Italian objective multicenter-study. Head Neck 2020, 42, 1560-1569. [CrossRef]

27. Salzano, F.A.; Mora, R.; Penco, S.; Traverso, D.; Gaggero, G.; Salzano, G.; Guastini, L. Nasal tactile sensitivity in allergic rhinitis. Acta Otolaryngol. 2011, 131, 640-644. [CrossRef]

28. Vaira, L.A.; Salzano, G.; Petrocelli, M.; Deiana, G.; Salzano, F.A.; De Riu, G. Validation of a self-administered olfactory and gustatory test for the remotely evaluation of covid-19 patients in home quarantine. Head Neck 2020, 42, 1570-1576. [CrossRef]

(C) 2020 by the authors. Licensee MDPI, Basel, Switzerland. This article is an open access article distributed under the terms and conditions of the Creative Commons Attribution (CC BY) license (http://creativecommons.org/licenses/by/4.0/). 